\title{
HIALINOSE CUTANEO-MUCOSA
}

\author{
RELATO DW: UM CASO \\ EDUARDO ABUJAMRA ASSEIS * \\ ROBERTO ADILSON DE MATTOS **
}

A hialinose cutâneo-mucosa é doença rara, transmitida por gene autossômico recessivo, descrita pela primeira vez por Urbach e Wiethe em 192911 . Até o momento foram publicados cerca de $200 \operatorname{casos}^{3,6,9}$. No Brasil, temos conhecimento de 6 casos publicados ${ }^{1}$. Caracteriza-se por rouquidão progressiva desde os primeiros meses de vida, baixa estatura, alopécia, alterações dentárias, lesões de pele e mucosas, fotossensibilidade e epilepsia ${ }^{5,7}$. O exame histopatológico da pele e dcmais tecidos do corpo mostra infiltrado de substância hialina, PAS (ácico periódico de Shiff) positivo. Em 1943, Ramos e Silva 8 descreveram cm um paciente imagens de calcificações intracranianas, bilaterais e simétricas, consideradas patognomônicas $\mathbf{4}, \mathbf{7}$.

A conveniência do seu melhor conhecimento motivou-nos a apresentar este caso.

\section{OBSERVAÇAOO}

V.O.A.B., feminina, 26 anos, natural de Porto Ferreira-SP, registro HCFMRP 013842. Apresentava rouquidão desde os três meses de idade, perceptível já no choro. Houve siora gradual desta rouquidão tendo atualmente acentuada disfonia. Desde os 6 meses de vida até a adolescência apresentoa lesões pust:-losas e bolhosas difusas em regiões expostas à luz solar que cicatrizaram com aspecto varioliforme. Tem lesões ulceradas em regiōes olecraneanas e patelares desde a infancia. Dos 7 aos 12 anos apresentou 4 crises epilépticas do tipo "déjà vécu", de curta duração. A partir dos 12 anos, época da menarca, tais manifestações passaram a ocorrer sistematicamente no período pré-menstrual, em número de 4 a 5 por mês. Fenobarbital, hidantoinato e carbamazepina, em doses habituais, isolados ou em associação não controlaram as crises. Teve dois filhos e durante os periodos de gestação não apresentou crises, mesmo sem o uso de drogas antiepilépticas. Segindo sua informação nunca teve crises do tipo convulsivo ou psicomotora. Seus pais, assim como seus avós maternos são primos em primeiro gráu. Não há quadro semelhante na família. Exame Físico - Tipo bre-

Trabalho realizado no Hospital das Clínicas da Faculdade de Medicina de Ribeirão Preto da Universidade de São Paulo (HCFMRP-USP): * Médico do Serviço de Neurocirurgia (Prof. Dr. Sylvio de Vergueiro Forjáz); ** Médico do Serviço de Dermatologia (Profa. Dra. Ana Maria Uthida Tanaka). 
vilíneo, baixa estatura $(155 \mathrm{~cm})$, fácies envelhecida, áreas de alopécia no couro cabeludo, ausência de dentes, mãos moderadamente hipoplásicas. A pele apresenta aspecto escleridermiforme difuso com cicatrizes atróficas e varioliformes difusas contendo pápulas perláceas ao longo das bordas livres palpebrais (Fig. 1) e nos dedos das mãos (Fig. 1) e dos pés. Observam-se pápulas hiperqueratósicas fissuradas nos joelhos
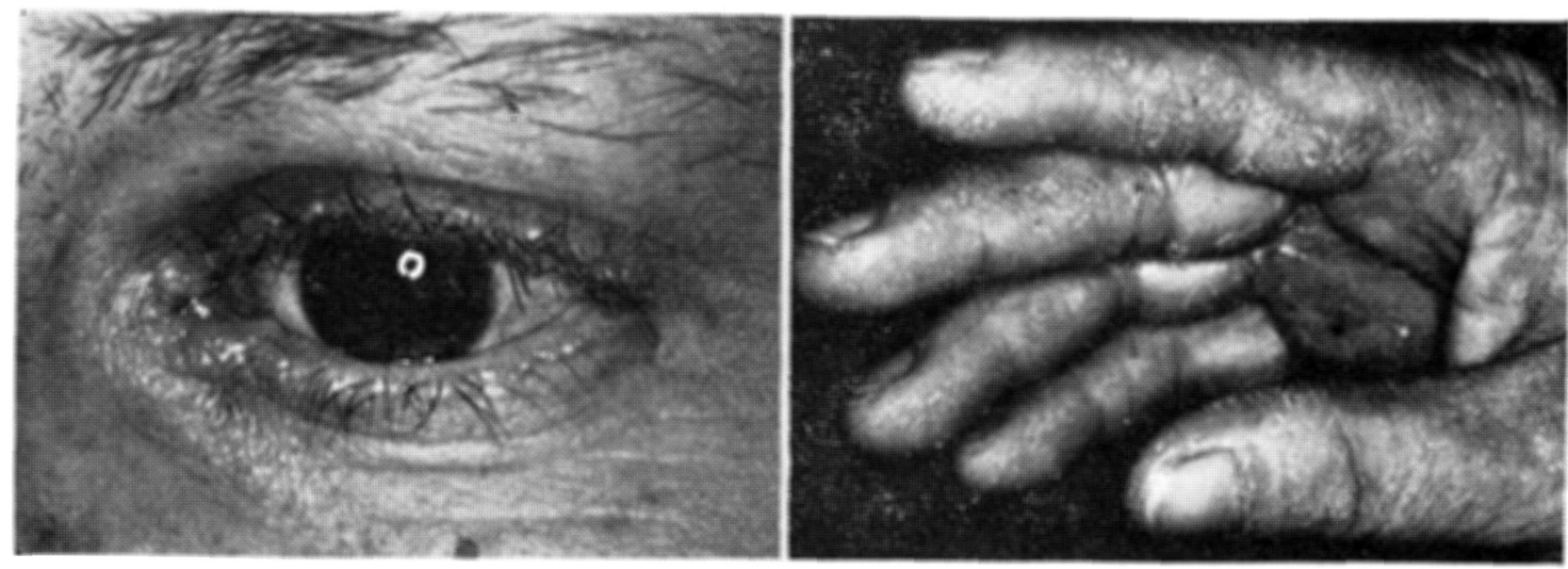

Fig. 1 - Caso V.O.M.B.: à esquerda, pápulas nas bordas livres das pálpebras; à direita pápulas em dedos da mão.
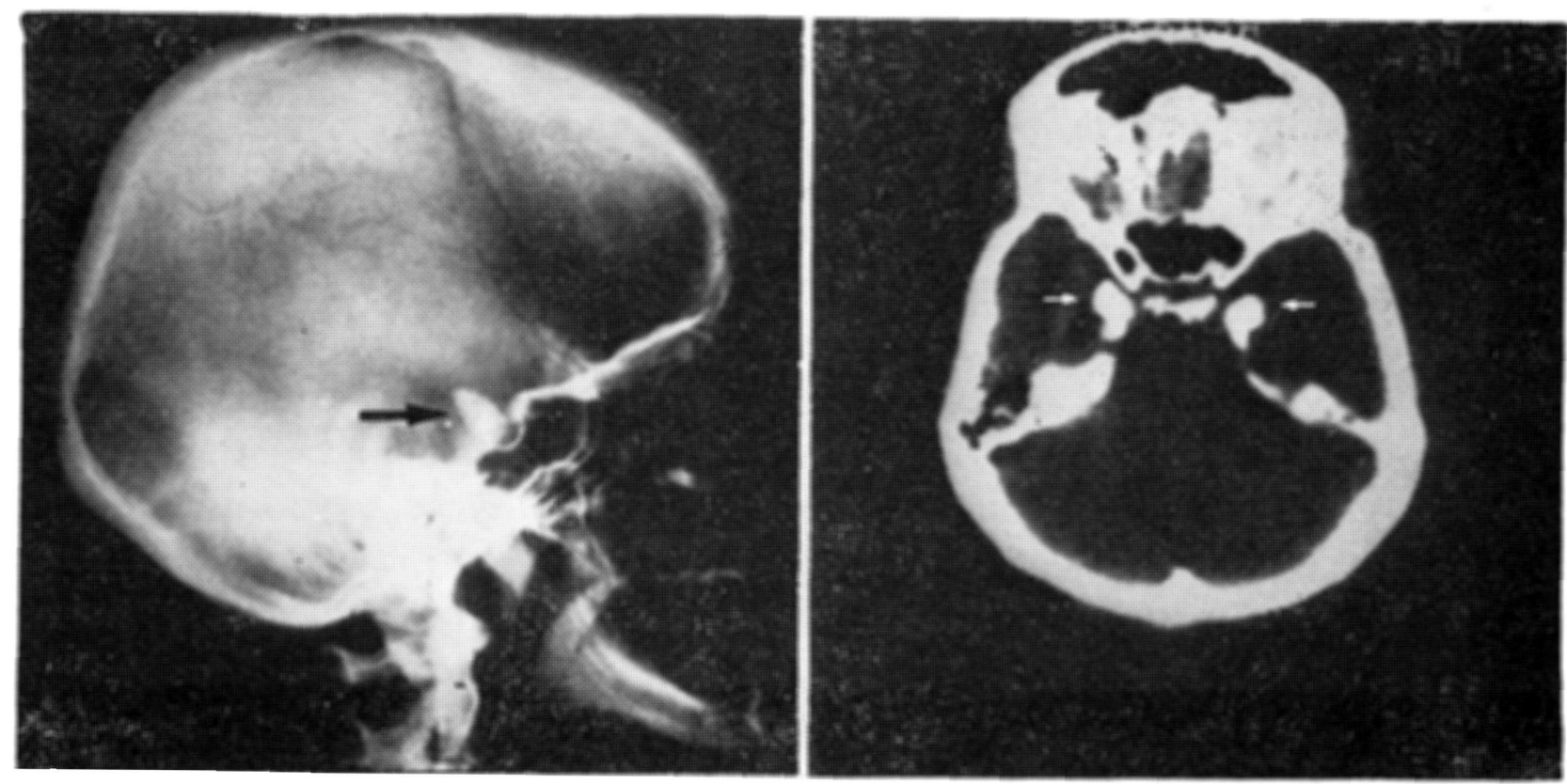

Fig. 2 - Caso V.O.M.B.: à esquerda, RX simples do cranio em perfil mostrando calcificação grosseira para-selar (seta); $\grave{a}$ direita, tomografia computadorizada do crânio mostrando calcificações intracranianas para-selares bilaterais e simétricas, em forma de vírgula (setas).

e regióes olecraneanas. Na cavidade oral encontram-se placas amarelo-esbranquiçadas em grande quantidade, estendendo-se para a orofaringe e região sub-lingual. A língua é de consistência fibrosa com acentuada limitação à protusão. $O$ exame neurológico não revela sinais de alteração. Exames complementares - hemograma, uréia, creatinina, 
transaminases, eletrólitos (sódio, potássio, cálcio, fósforo, magnésio) fosfatase alcalina, glicemia, colesterol, triglicerídios, eletroforese de proteínas e lipídios plasmáticos, uro e coproporfirinas normais. Biópsia de mucosa de lábio inferior e pele do cotovelo, coradas pela hematoxilina e eosina apresentam depósito de substância hialina disposta perpendicularmente à superfície da derme, compatível com o diagnóstico de hialinose citâneo-mucosa. Reação com PAS positiva. O exame eletrencefalográfico mostra apenas discreto alentecimento dos ritmos cerebrais durante a hiperventilação. $O$ exame do líquido cefalorraqueano é normal. O exame radiológico do crânio mostra imagens de calcificações grosseiras de localização para-selar (Fig. 2). A tomografia computadorizada do crânio são vistas em forma de vírgula, simétricas e projetando-se ao nível dos corpos amigdalóides (Fig. 2).

\section{COMENTARIOS}

Os sinais e sintomas desta paciente são clássicos de hialinose cutâneomucosa. A infiltração hialina observada na biópsia de pele é típica; sendo responsável pelas lesões cutâneo-mucosas e pela rouquidão, devido a infiltração da laringe ${ }^{6}$. Urbach e Wiethe atribuiram-na a depósitos de fosfatideos e proteinas, sugerindo o termo lípido-proteinose r; estudos recentes sugerem tratar-se de depósitos de glicoproteínas mas a sua natureza não está determinada ${ }^{2}$. As calcificações intracranianas para-selares, em forma de vírgula, são consideradas patognomônicas, e observadas em cerca de $50 \%$ dos casos. Meenan et col.6 descreveram no exame de necrópsia de paciente com hialinose cutâneo-mucosa calcificações grosseiras no uncus e porções adjacentes do giro para-hipocampal. Lesões semelhantes, porém pouco calcificadas, não visíveis macroscopicamente, foram encontradas no córtex cerebral e substância branca profunda dos lobos frontal, parietal e temporal. Estas calcifiçações para-selares devem ser diferençadas das calcificações simétricas dos núcleos da base, devidas principalmente ao hipoparatireoidismo, síndrome de Fahr e síndrome de Cockayne ${ }^{10}$. Sendo as crises epilépticas do tipo "déjà vécu" manifestações do lobo temporal, é possível que as calcificações cranianas descritas no exame radiológico sejam a sua causa. Estas crises manifestaram-se sistematicamente no período pré-menstrual e cessaram nos períodos de gestação. Não foram controladas com $o$ uso de medicação anti-epiléptica.

\section{RESUMO}

Apresenta-se o caso de uma paciente com hialinose cutâneo-mucosa e comentam-se os aspectos neurológicos, radiológicos e dermatológicos. Evidencia-se a presença de calcificações intracranianas comprovadas no exame radiológico, consideradas patognomônicas.

\section{SUMMARY}

Hyalinosis cutis et mucosae: a case report.

The clinical case of a patient with hyalinosis cutis et mucosae is reported, and the neurological, radiological and dermatological aspects involved are dis- 
cussed. We point out the presence of intracranial calcifications, demonstrated by radiological examination, considered to be pathognomonic.

\section{REFERENCIAS}

1. ASSEIS, E.A.; PRISCINOTTI, T. \& SCHINITZLER, R. - Hialinose cutaneo-mucosa: Apresentação de um caso. An. bras. Dermat. 56:209, 1981.

2. BAUER, E.A.; SANTA CRUZ, D.J. \& EINSEN, A.Z. - Lipoid proteinosis: in vivo and in vitro evidence for a lysosomal storage disease. J. Invest. Dermat. 76:119, 1981.

3. BERGENHOLTZ, A.; HOFER, P.A. \& OHMAN, J. - Oral, pharyngeal and laringeal manifestations in Urbach-Wiethe disease. An. clin. Res. 9:1, 1977.

4. FRANCIS, R.S. - Lipoid proteinosis: a case report. Radiology 117:301, 1975.

5. HOFER, P.A.; LARSSON, P.A.; EK, B.; GOLLER, H.; LAURELL, H. \& LORENTZON, R. - A clinical and histopathological study of twenty-seven cases of Urbach-Wiethe disease. Acta path. microbiol. scand., section A, suppl. 245, 1974.

6. MEENAN, F.O.C.; BOWE, S.D.; DINN, J.J.; MCCABE, M.; MCCULLEN, O.; MASTERSON, J.C. \& TOWERS, R.P. - Lipoid proteinosis; a clinical, pathological and genetic study. Q.J. Med. (New Series XLVII) 188:549, 1978.

7. NEWTON, F.H.; ROSENBERG, R.N.; LAMPERT, P.W. \& BRIEN, J.S. - Neurologic involvement in Urbach-Wiethe's disease (lipoid proteinosis). Neurology (Minneapolis) 21:1205, 1971.

8. RAMOS E SILVA, J. - Lipoid proteinosis (Urbach-Wiethe). Arch. Dermat. (Chicago). 47:301, 1943.

9. ROOK, A. - Lipoid proteinosis: Urbach-Wiethe disease. Brit. J. Dermat. 94:341, 1976.

10. TAVERAS, J.M. \& WOOD, E.H. - Diagnostico Neuro-Radiológico. Ed. Médica Panamericana, Buenos Aires, 1978.

11. URBACH, E. \& WIETHE, C. - Lipoidosis cutis et mucosae. Virchow Arch. path. Anat. 27:285, 1929.

Hospital das Clínicas, F'MRP-USP - 14100, Ribeirão Preto, SP - Brasil. 